\title{
Study on Legal Problems Existing in Prepaid Cards in China
}

\author{
Changyue Shen \\ North China Electric Power University \\ Baoding, Hebei, China
}

\author{
Wen Cong \\ North China Electric Power University \\ Baoding, Hebei, China
}

\begin{abstract}
As a new consumption pattern, the prepaid consumption has a realistic base for its rising and development and it plays an important role in promoting the rapid economic development. In practice, the prepaid consumption is mainly achieved through the prepaid cards, for the capital is of prepayment, and it belongs to a consumption based on the credit mechanism, there is no sound credit evaluation mechanisms in China, and the lower default costs have caused a confused development of the prepaid consumption, a shock to the current economic order and serious infringement to the legal rights and interests of consumers. In order to prevent the expansion of its negative functions, laws and regulations shall be used to govern the prepaid consumption from many aspects.
\end{abstract}

Keywords—prepaid consumption; law; rules and systems

\section{INTRODUCTION}

As the economic development goes rapidly, the living level of the people is being improved continuously, and the purposes and patterns of consumption are also changing. During the course of daily consumption, the consumption aiming to solve food and clothing supplies in the past has been gradually changed to an action for purposes of satisfying the needs of materials and spirits. Due to the changes in consumption structure, the consumption patterns are also diversified.

\section{Status QUO OF CONSUMPTION VIA PREPAID CARDS}

The increased needs in consumption have created a new consumption pattern, namely the prepaid consumption, which currently has been widely used and promoted in all fields and gradually integrated to the daily consumption. Main reasons for the rapid development of the prepaid consumption in practice are its satisfaction to the following: First, consumer's demand for goods or services preference, and the need of convenient transactions; Second, the demand of operators for stable customers and adequate cash flow. In practice, the operators may take the prepayment of customers as a means of financing in order for capital turnover and ease financial difficulties, besides, the operators may attract a great number of customers so as to establish stable customers and lay a solid foundation for development; Third, the needs of new transaction patterns under the rapid economic development. The development of economy and technology has made the traditional transaction "both sides clear" unsuitable for the

Fund Project: North China Electric Power University Project Supported by Fundamental Research Funds for Central University, State Grid-Study on Social Responsibilities for Enterprises in China Under the View of Law, Project Code (9161214009) development, and more strict requirements are raised for the diversification of logistics, trading modes and stakeholders, meanwhile, commercial banks have no stable financial instruments applicable for the daily consumption of consumers thus the consumption via prepaid cards obtain a great opportunity for development. The healthy growth of consumption via prepaid cards will certainly be a must to drive the development of market economy. However, there are still no special financial laws related to the consumption via prepaid cards, during the development of prepaid consumption, especially the prepaid cards issued by dealers will cause risks in commerce and law in practice, therefore, it is urgent to establish special laws and regulations to govern the prepaid consumption.

\section{RATIONALITY OF PREPAID CARDS}

The prepaid consumption is an outcome after the social and economic development reaches to a certain stage, seen from the current status quo, although the management is imperfect and higher risks are potential for consumers, according to the theory of risk society, the risks existing in many things newly arising are inevitable, but compared to the social benefits they bring, the risks can be tolerated to some degree, therefore, the prepaid consumption is rational relatively and specified as follows.

- Seen from buyers, it is very easy to handle procedures of consumption cards, and the card buyers pay the card purchase funds to the card issuers which will offer commercial prepaid cards with the same value as the funds to the buyer. It is easy for accounting, and the buyers and individuals may issue different commercial invoices as per the financial purposes. Besides, it can reduce the cash flow and make it easy to carry and the convenient prepaid cards may well change the cash preference of customers and lower the cash transaction greatly. For customers, through the prepaid consumption, they could obtain discounts or preferences offered by dealers; facing the same goods and service, the customers may purchase in a low price, it has obvious advantages in price, which will do good to stir the consuming desires of consumers.

- Seen from the market economy, on the one hand, it may relieve the pressure in operation, with the widening of consumption field, the competition in all fields and trades are hot. In order to retain customers 
and occupy the market share and provide more convenient service to consumers, no doubt the pattern has become a new path for dealers to survive, which could ensure customer sources in advance and buffer the operating pressure. On the other hand, after a new consumption pattern emerges, for the consumption market, to some degree the prepaid consumption will help to form a steady and long term consumption relations between dealers and consumers on the basis of trust, which will do good to activate the market, promote friendly competition between dealers and urge the them to improve the service quality so as to purify the market environment. Besides, the prepaid consumption may drive the e-commerce, and the promotion and use of commercial prepaid cards will bring an active push to the e-commerce development.

- Seen from dealers, the prepaid consumption enables the dealers to obtain consumption funds in advance from consumers, which may lower the dealers' operation costs and guarantee the capital chain and do good to the capital turnover. With the economic resources from customers occupied, the dealers may expand the operation or invest to achieve the capital added value and positive cycle.

\section{PROBLEMS EXISTING IN THE CONSUMPTION VIA PREPAID CARDS}

\section{A. Hard to Protect the Rights and Interest of Consumers}

It is often reported that dealers escape after collecting lots of member costs in practice, there are many victims of such cases, Ms Liu in Jiangsu Province paid 1,600 yuan or so for a beauty card at a beauty store close to the quarters where she lived, when she was free and went to enjoy the beauty service at the weekend, the beauty store was closed already, which had been changed into a fried dumplings restaurant. The boss of the beauty store escaped, and she received one beauty care only with the 1,600 yuan. The consumer was cheated by the dealer who cheated and collected the funds maliciously, and the imparity clause (namely a formatted clause in contracts) will do bad to protect the rights and interests of consumers. The dealers refuse to repay the balance of consumers, namely the balance of consumers is confiscated directly by the dealers, and clauses can be found in cases as: after the member fee is paid, it shall not be repaid. The rights consumers to select of are deprived also by the imparity clause. According to Item 1 of Article 9 of the Law of the PRC on the Protection of the Rights and Interests of Consumers, it is stipulated that a consumer shall have the right to free choice in purchasing commodities or services. In fact, though preferential conditions are offered to attract consumers to the member system, the dealers restrict the preferential scope, consumption time and service type. For example, some mobile agents often launch "return to customers" activities, but some business will be bound, the binding and forced consumption seriously deprive the rights of consumers to select and violate the rights of property of consumers. Many consumption cards carry the final rights for interpretation, if any dispute arises, the issuers or dealers often take the clause "Our store owns the final rights for interpretation" for defense. In fact, the cause for defense is invalid. If it not stated or disputed in contracts, the parties concerned should negotiate for settlement. The clause of final rights for interpretation is contrary to the fairness principle, which violates Article 40 of the Contract Law and shall be considered invalid. Besides, the interpretation to formatted clause will not certainly depend on the opinions of a party providing the text. According to Article 41 of the Contract Law, if the interpretation to a formatted clause is disputed, it shall be interpreted against the party providing the format.

\section{B. Difficulty in Establishing Systems of Prepaid Consumption} Makes It Hard for Consumers to Protect Theri Rights and Interests, Based on Which, Dealers May Commit Illegal Activities

Currently there are no special laws or regulations for the prepaid consumption market, due to the lack of basis for supervision, it's difficult for relevant authorities to supervise. The market economy makes a rapid progress yet the market supervision falls behind, because of such reasons, the prepaid consumption has brought some negative impacts to the economic development, meanwhile, the prepaid consumption is a new thing, and its development is also unpredictable, besides, it is of higher complication, which increases the difficulty of law making for the prepaid consumption. Due to the lack of laws and regulations to govern the prepaid consumption, as far as the consumers, the information asymmetry and the misuse of advantageous position by dealers in market make it much more serious. Consumers master goods information only through the dealers, yet most dealers may possibly exaggerate the product quality to attract more customers in order to earn more, which can cause the difference from the product, facing the situation, the consumers may have their rights and interests infringed, but there are no relevant laws and regulations available, so it is difficult to protect their rights and interests. The prepaid consumption makes it possible for the dealers with criminal intents for financing illegally, and the prepaid consumption is used by criminals to conceal sources of earnings and benefits and escape from the anti-money laundering supervision. As such, the consumption which aims at promoting the economic development becomes a tool for criminals, and the economic development is seriously impacted.

\section{SugGeStions to IMPROVE THE PREPAID CONSUMPTION FOR HEALTHY DEVELOPMENT}

\section{A. Establish Uniform Laws and Regulations to Govern the Commercial Prepaid Cards}

Carry out the prepaid card access system, strengthen examination on the qualification for the prepaid card access and conduct risk evaluation on the loan repayment capability such as registered capital, business scope, scale and mode so as to prevent the disqualified dealers from entering the prepaid card market. Meanwhile, carry out the filing system, managing authorities should make thorough surveys on the dealers which have adopted the prepaid card consumption, and make filing of risk evaluation, credit level, operation conditions and so on, and release consumption warning against improper operation 
through consumer committees so as to protect the interest of consumers. Start with protection, card purchase, card use and card quit, focus on the dispute settlement, establish a protective mechanism for card holders, and protect the economic benefits of consumers from being infringed.

\section{B. Establish Performance Security Systems}

The consumption via prepaid cards is a disguised, one-way and long term credit granted by most consumers to dealers, during the consumption, the consumers will pay before consumption, a credit is granted by consumers to dealers, besides, many consumers grant credits to one dealer, the credit granted by a weak side to a strong side belongs to commercial credit. After making payment, the consumers will have lost the initiative and the right of choice. The realization of financial claims shall depend on the willingness for repayment and liquidity of debtors. However, the operation mode of borrowing money for making profits proves that the liquidity of the dealers has birth defect, and the lack of social credit system facilitates the arrogance of avoiding debts. The prepaid consumption must be in a shadow of credit crisis. The base of prepaid consumption is credit, yet the credit cannot be separated from the security, the performance security can not only restrict behaviors of enterprises, but also strengthen social responsibilities of their own and promote the construction of social credit system.

\section{Consumers Should Set up Consciousness of Risks and Rights Protection}

There are risks existing in the prepaid consumption, which consumers should be aware of and improve the consciousness of risks, and pay attention to the operation of dealers, and quit cards immediately if the credits of the dealers are poor. Consumers should select operators with a large scale and high reputation and sign formal written contracts, carefully read the contents especially restricting conditions and imparity clauses therein. Meanwhile, consumers should avoid one-off excessive capital, keep original receipts, and seek for assistances at the consumers association in case of any dispute, and report to the administration for industry and commerce if necessary. Besides, before the establishment of relevant laws and regulations, consumers should first know about information of the enterprises before handling cards but not blindly believe advertisements or oral promises, the one-off card amount shall not be excessive, do not just seek the cheapness but ignore risks potential. Refuse unfair formatted contracts and report in time in case of rights infringement.

\section{Relevant Departments Shall Strengthen Publicity and Instruction to Guide Rational and Efficient Consumption}

On the one hand, strengthen the publicity of relevant laws and regulations and improve the legal consciousness of consumers; On the other hand, collect lots of typical cases for consumption warning. Cases can be used to make consumers know risks potential for the prepaid consumption, and improve the capabilities of consumers to identify counterfeits and misleading publicity and increase the capabilities to avoid risks in consumption. Meanwhile, relevant authorities should clear the responsibilities of card issuers for anti-money laundering, and rules shall be specified for the card issuers or the card suppliers to take responsibility for anti- money laundering, and bear obligations for identification of clients' status, report of doubted transaction, clients' identity data and keeping of transaction record, etc. The systems are used to restrict the card issuers and contract signing units for anti- money laundering and lower the criminal acts through the commercial prepaid cards.

\section{CONCLUSION}

The risks existing in the prepaid cards have many sources, including market, ethic and even law, and other risk factors are easy to access to the new consumption pattern with the development of the time, facing the complicated and changing environment, the establishment of laws and regulations are inadequate to govern, scientific methods should be adopted to govern the prepaid consumption according to conditions in practice. The law making for the prepaid consumption is systematic and complicated, which will be involved in the issuing systems and supervision systems as well as the rights and obligations of those concerned; besides, the lawmaking for the prepaid consumption is not isolated, which shall be included in the legal system of commercial payment on the basis of cash, bill, bank cards and so on. With the economic development, the prepaid consumption may have new characteristics and new problems, accordingly the problems concerning the prepaid consumption still need further and continuous study. According to the actual conditions, well govern the prepaid consumption, exert the favorable role of its own to drive the economy and remove its negative effect in the course of development.

\section{REFERENCES}

[1] Yang Lixin, Liu Huan, Responsibility for Breach of Contract and System Improvement for the Prepaid Consumption [J]. Study on China Administration for Industry \& Commerce 2013,(3).

[2] Wang Jianwen, Laws and Regulations for the Prepaid Consumption Modes in China [J]. Science of Law, Journal of Northwest University of Political Science and Law 2012, (5)

[3] Ye Lin, Laws Governing Contracts of Prepaid Consumption [J]. Journal of Harbin Institute of Technology, Social Sciences Edition, 2011, (2)

[4] Duan Baomei, Discussion Legal Problems Concerning the Prepaid Consumption [J]. Journal of Shanghai Business School, 2010, (2).

[5] Du Xiaoyu, Laws and Systems for Prepaid Cards in Japan and Its Reference for China [J]. Financial Review in Beijing, 2012, (3).

[6] Xu Xiaofei, Legal Risks Urgent for Prevention in the Prepaid Consumption [J]. Inside and Outside of Court, 2015, (1).

[7] Zhu Jindong, Sun Tingting, Legal Establishment of Performance Security System for the Prepaid Consumption in China [J]. Dongyue Tribune, 2014, (3)

[8] Huang Zongde, Positions and Rights Protection of Consumers in the Prepaid Consumption [J]. Journal of Heilongjiang College of Education2012, (12).

[9] Xia Dan, Sun Lei and Wu Jianfei, Visible and Invisible Risks [N] Xinhua Daily, 2011-4-25, (05). 